\title{
GEOMETRIC MEANS OF TWO POSITIVE NUMBERS
}

\author{
Raghib M. AbU-SARIS AND MOWAFFaQ HaJJA
}

\begin{abstract}
We introduce three families of means that encompass several classical means that arise naturally in geometric contexts. Within these families, we discuss dominance relations, closure under Gauss' compounding, behavior under equal increments, and other related issues.
\end{abstract}

Mathematics subject classification (2000): 26D05. cubic means.

Key words and phrases: internality, means, root quadratic means, rational quadratic means, rational

\section{REFERENCES}

[1] R. Abu SARIS, M. HAJJA, Quadratic means, J. Math Anal. Appl., 288, (2003), 299-313.

[2] J. ACZÉL, Zs. PÁLES, The behaviour of means under equal increments of their variables, Amer. Math. Monthly, 95, (1988), 856-860.

[3] J. ACZÉL, L. LOSONCZI AND Zs. PÁLES, The behaviour of comprehensive class of means under equal increments of their variables, Numerical Mathematics, 80, 856-860, Birkhäuser Verlag, Basel, 1987.

[4] J. M. Borwein, P. B. Borwein, The way of all means, Amer. Math. Monthly, 94, (1987), 519-522.

[5] J. M. BORWEIN, P. B. BoRWEIN, Pi and the AGM - A Study in Analytic Number Theory and Computational Complexity, Wiley, New York, 1986.

[6] C. B. BOYER, A History of Mathematics, John Wiley and Sons, Inc., New York, 1968.

[7] P. S. Bullen, Handbook of Means and Their Inequalities, Kluwer Academic Publisher, Dordecht, Holland, 2003.

[8] P. S. Bullen, Averages still on the move, Math. Mag., 63, (1990), 250-255.

[9] D. BuRTON, The History of Mathematics, Allyn and Bacon, Inc., Boston, 1985.

[10] M. D. ChOI, T. Y. LAM AND B. ReZnick, Even symmetric sextics, Math. Z., 195, (1987), 559-580.

[11] B. C. DiETEL, R. A. Gordon, Using tangent lines to define means, Math. Mag., 76, (2003), 52-61.

[12] D. Cox, Gauss and the arithmetic-geometric mean, Notices Amer. Math. Soc., 32, (1985), 147-151.

[13] D. Cox, The arithmetic-geometric mean of Gauss, Enseign. Math., 30, (2) (1984), 275-330.

[14] H. Eves, A Survey of Geometry, Revised edition, Allyn and Bacon, Inc., Boston, 1978.

[15] H. Eves, Great Moments in Mathematics (before 1650), Doliciani Math. Exp., No. 5, Math. Assoc. America, Washington, DC., 1980.

[16] H. Eves, An Introduction to the History of Mathematics, 5th edition, Saunders, Philadelphia, 1983.

[17] H. Eves, Means appearing in geometric figures, Math. Mag., 76, (2003), 292-294.

[18] D. FARNSWORTH, R. ORR, Transformation of power means and a new class of means, J. Math Anal. Appl., 129, (1988), 394-400.

[19] B. DE FINETTI, Theory of Probability, Vol. 1, Wiley, London, 1974.

[20] M. HAJJA, Copositive symmetric cubic forms, Amer. Math. Monthly, 112, (2005), 462-466.

[21] L. HoEHN, I. Niven, Averages on the move, Math. Mag., 58, (1985), 151-156.

[22] P. T. LANDSBERG, A generalized mean, J. Math. Anal. Appl., 76, (1980), 209-212.

[23] M. E. MAYs, Functions which parametrize means, Amer. Math. Monthly, 90, (1983), 677-683.

[24] D. MoskoviTZ, An alignment chart for various means, Amer. Math. Monthly, 40, (1933), 592-596.

[25] K. B. Stolarsky, Cubic triangle inequalities, Amer. Math. Monthly, 78, (1971), 879-881.

[26] P. YIU, Notes on Euclidean Geometry, http://www.math.fau.edu/yiu 